\title{
EFFECT OF ND:YAG LASER HYALOIDOTOMY FOR PREMACULAR SUBHYALOID HAEMORRHAGE
}

\author{
Gyanendra Lamichhane ${ }^{1}$, Sweta Singh ${ }^{1}$
}

\begin{abstract}
INTRODUCTION: Premacular subhyaloid hemorrhage is a common condition leading to severe sudden vision loss in various conditions. This study investigated the effects of drainage of premacular subhyaloid hemorrhage into the vitreous with Nd:YAG laser treatment. Photodisruption with Zeiss Nd.Yag laser done in the inferior part of the the hemorrhage to create hole in ILM for gravitational drainage of blood in vitreous. A rapid resolution of subhyaloid hemorrhage with improvement of visual acuity was achieved in all patients treated with Nd:YAG laser posterior hyaloidotomy, without evidence of damage to the retina or choroid. Nd:YAG laser posterior hyaloidotomy is simple, effective, safe and non invasive procedure for draining a premacular hemorrhage into the vitreous cavity and to avoid vitreoretinal surgery and complication related to long standing macular toxicity by blood.
\end{abstract}

KEYWORD: Premacular subhyaloid hemorrhage, Nd: yag laser, Vitreous hemorrhage

1. Ophthalmologist, Department of Vitreoretina, Lumbini Eye Institute, Shree Rana-Ambika Shah Eye Hospital, Bhairahawa, Nepal

\author{
For Correspondence \\ Dr. Gyanendra Lamichhane \\ Ophthalmologist, \\ Department of Vitreoretina, \\ Lumbini Eye Institute, Shree Rana-Ambika Shah \\ Eye Hospital ,Bhairahawa, Nepal \\ E-mail:yourgyanu@gmail.com
}




\section{INTRODUCTION}

Premacular subhyaloid haemorrhage refers to blood accumulation in the subhyaloid or the retrohyaloid space, which lies between the posterior hyaloid face and the internal limiting membrane of the retina. Premacular subhyaloid hae morrhage has a circular shape in beginning and later assumes a hemispherical configuration with a straight upper margin due to the effect of the gravity and typically is boat shaped ${ }^{1}$. It can occurs in vascular disorders such as proliferative diabetic retinopathy, branch retinal vein occlusion and retinal macroaneurysm. It may also occur in valsalva retinopathy and in association with haematological disorders. ${ }^{2}$ It is a cause of abrupt and severe loss of vision. Major conventional treatment options are observation (to allow spontaneous clearance) and vitrectomy. The spontenous reabsorption rate is so slow, taking several months to years. The toxicity potential of blood may cause macular damage, epiretinal membrane formation, macular traction and retinal detachment resulting in permanent visual loss. Nd:YAG laser can produce a defect in the posterior hyaloid/internal limiting membraneallowing rapid diffusion of hemorrhage into the vitreous gel thus clearing the visual axis and allowing faster absorption of blood $^{3}$ and can protect from all complication.

\section{MATERIALAND METHODS}

Pulsed Nd:YAG laser posterior hyaloidotomy with The VISULAS YAG II plus; Zeiss system was used. After full pupillary dilatation and topical anesthesia, central mirror of a Goldmann three mirror contact lens was used to focus the $\mathrm{Nd}$ :YAG aiming beam so that an opening in the posterior hyaloidmembrane near the inferior edge (i.e apex of the triangular subhyaloid hemorrhage)avoiding retinal blood vessels and fovea could be made.

$\mathrm{Nd}$ :YAG laser power starting from low power of $3.5 \mathrm{~mJ}$ to gradually increasing until it created hole in posterior hyaloid applied. Finally with power $10 \mathrm{~mJ}$ was used and the number of applications varied from one to five strategically placed impacts to achieve the needed aperture through the posterior hyaloid membrane. Pre and post treatment examination included visual acuity on Snellen's chart, fundus examination by direct ophthalmoscopy and slit lamp biomicroscopy with +90 D Volk lens for posterior pole examination. A detailed peripheral retinal examination with indirect ophthalmoscope and scleral indentation was also done to rule out any other peripheral retinal lesion or retinal vascular diseases. After laser treatment patient was advised head end elevated position till the blood cleared from the visual axis. The patient was asked to followed up at 1 week and 3 weeks after procedure. Conservative management involved regular follow-up of the patients with topical weak steroid and oral steroid $1 \mathrm{mg} / \mathrm{kg} / \mathrm{d}$ for 1 week without any surgical intervention until spontaneous resolution of the hemorrhage was complete.

\section{CASE HISTORY}

25 yrs female presented with sudden blurred vision in the right eye that since 2 days. She did not give any significant history of trauma or known systemic illness for which she is under treatment. Ophthalmological examination revealed visual acuity to be light perception (PL)and accurate projection (PR)in the right eye and $6 / 6$ in the left eye. Slit-lamp biomicroscopy revealed a normal anterior segment in each eye. Intraocular pressure was $14 \mathrm{~mm} \mathrm{Hg}$ bilaterally. Fundoscopy of the right eye revealed a round, well circumscribed, partially dark red haemorrhage covering the macula and posterior pole. (Fig. 1)

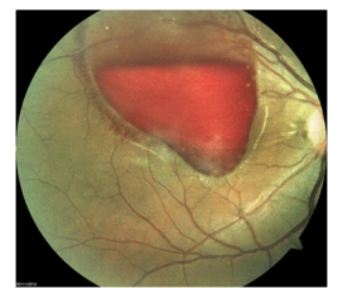

Figure1:Premacular subhyaloid haemorrage at presenation

The shape of the haemorrage was triangular with apex pointing downward. There was a fluid level in the upper part of the haemorrhage. Fundoscopy was completely normal in the left eye. As we don't have hemaltologist so We consulted the patient with physisican for any systemic condition but physical examination and laboratory investigations including complete blood counts, bleeding and clotting times, peripheral smear andplatelet normal.

The anterior surface of the haematoma was opened with $\mathrm{Nd}$ :YAG laser with $10 \mathrm{~mJ}$ energy inferiorly at the apex of the triangle. Blood sequesturated under the posterior hyaloid membrane immediately under the influence of the gravity.

(Fig. 2)

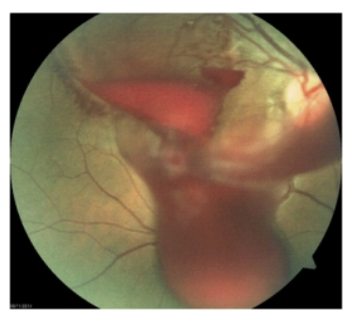

Figure 2: Immidietly after Yag Laser Hyaloidotomy.Note the blood is trickling down to Vitreous cavity 
The patient was prescribed weaker steroid eye drop flurometholone four times per day for 1 week and oral steroid prednisolone $1 \mathrm{mg} / \mathrm{kg} / \mathrm{d}$ for 1 week and asked to follow up after 1 week. On 1 week follow up, the visual acuity of the patient improved to $6 / 9$, biomicroscopic examination was bilaterally normal and intraocular pressure measurements were 14 $\mathrm{mmHg}$ bilaterally. At fundoscopy, preretinal haemorrhage obscuring the macula had cleared completely with slight trace of blood superiorly and slight turbidity of retina secondary to vitreal dissemination of the haemorrhage. (Fig.3)

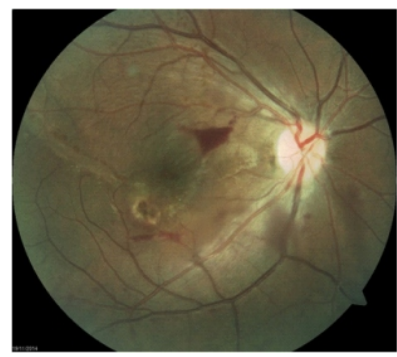

Figure 3: 1 Week after Laser Hyaloidotomy.Note only very little residual blood in macular region.

\section{DISCUSSION}

Drainage of premacular subhyaloid haemorrhage into the vitreous with an $\mathrm{Nd}$ :YAG laser was successfully achieved without any clinical evidence of damage to the underlying retina or choroid. This is quite similar with the results of other series ${ }^{2,4}$ which resulted in hastened improvement of vision to normal or premorbid level. Puthalath ${ }^{5}$ used frequency doubled $\mathrm{Nd}$ :YAG laser $(532 \mathrm{~nm})$ to treat subhyaloid haemorrhage of different causes. They noticed poor visual improvement in proliferative diabetic retinopathy associated with clinically significant macular oedema. Eyes with premacular subhyaloid haemorrhage resulting from Valsalva retinopathy had a good visual recovery. Complete intravitreal drainage of the blood occurred within a week following $\mathrm{Nd}$ :YAG laser hyaloidotomy and visual improvement occurred within one week. Pretreatment duration of premacular subhyaloid haemorrhage seems to be of prognostic importance. Our findings are in support of good prognosis in Valsalva retinopathy cases. Since we could not establish any confirmatory cause for the haemorrage after history and investigation, we considered as Valsalva retinopathy assuming that there may be minor events leading to valsalva retinopathy but she was not be able to recall Visual improvement was near normal (6/6 to 6/9) Clinical examination revealed no evidence of retinal or choroidal hemorrhage, retinal pigment epithelial changes, from $\mathrm{Nd}$ :YAG laser treatment in any of the patients in this series. As blood, hemoglobin, and iron have a toxic effect on the retina. ${ }^{6}$
It is justificable to drain this blood in order to prevent macular damage and other blinding complications.

\section{CONCLUSION}

Photodisruptive Nd:Yag Laser hyalotomy is the simple safe and effective way of treatment for dense premacular subhyaloid haemorrage causing marked vision loss. This can avoid the need of invasive vitreoretinal surgery and its complications.

\section{REFERENCES}

1. Duke-Elder S, Dobree JH. System of Ophthalmology.Vol10; St. Louis. CVMosby, 1967;145-7

2. Spraul CW \& Grossniklaus HE (1997): Vitre- ous hemorrhage. SurvOphthalmol 42: 339.

3. Raymond LA. Neodymium: YAG Laser treatment for hemorrhages under the internal limiting membrane and posterior hyaloid face at the macula. Ophthalmology. $1995 ; 102: 40611$

4. Isaacs TW, Barry C, McAllister IL. Early resolution of premacularhemorrhage following $N d: Y A G$ laser photodisruption of posterior hyaloid. Aust NZ J Ophthalmol. 1996;24:3657.

5. Puthalath $S$, Chirayath A, Shermila $M V$, Sunil MS, Ramakrishanan R. Frequency doubled Nd:YAG laser treatment for premacularhaemorrhage. Ophthalmic Surg Lasers imaging 2003; 34(4):284-90.

6. Forrester JV, Grierson L, Lee WR. Vitreous membrane formation after experimental vitreous hemorrhage. Albrecht Von Graefes Arch KlinExpOphthalmol. 1983;212:22742 